\title{
Genetic, Chemical, and Biological Diversity in Mangifera indica L. Cultivars
}

\author{
Seham S. El-Hawary*, Rehab M. S. Ashour*, Sabah H. El-Gayed, Haidy A. Gad', Gehad A. Abdel Jaleel², \\ Rania A. El Gedaily \\ Department of Pharmacognosy, Faculty of Pharmacy, Cairo University, 'Department of Pharmacognosy, Faculty of Pharmacy, Ain Shams University, Cairo, \\ 2Department of Pharmacology, National Research Center, Giza, Egypt \\ *These authors contributed equally to this work.
}

\begin{abstract}
Context: Mango is a valuable plant with vital economic importance; the leaves of its cultivars show several morphological similarities. Aims: Full differentiation of the leaves of eight Mangifera indica L. cultivars depending on genetic, chemical, and biological bases. Settings and Design: Chemometric analysis was applied to fully distinguish the diversity among cultivars; also, their gastroprotective activity was studied. Subjects and Methods: DNA fingerprinting of eight mango cultivars using random amplified polymorphic DNApolymerase chain reaction technique and high-performance liquid chromatography (HPLC) analysis of phenolic compounds and flavonoids were compared using chemometric analysis. Furthermore, estimation of total polyphenolics and flavonoids and gastroprotective activity was studied. Statistical Analysis Used: One-way analysis of variance was used, followed by Tukey's post hoc test. Results: Primers OPA-O7 and OPA-O8 showed $100 \%$ polymorphism. Total polyphenolics and flavonoids concentrations varied greatly (14.58 in Tommy atkins to 29.54 in Fagrklan $\mathrm{g}$ gallic acid equivalent/100 g extract and $22.49 \mathrm{in}$ Tommy atkins to $93.40 \mathrm{in}$ Fagrklan g rutin equivalent/100 g extract, respectively). HPLC quantification revealed that Kent had relatively high mangiferin content $(732.446 \mathrm{mg} / \mathrm{kg}$ ), and caffeic acid was recorded in the tested cultivars (2266.66 in Keitt to $1106.94 \mathrm{mg} / \mathrm{kg}$ in Naaomy). Pylorus ligation model in rats was used to assess gastroprotective potential at a dose of $200 \mathrm{mg} / \mathrm{kg}$ using standard ranitidine. High percentage protection was observed in Kent $(65.62 \%)$, whereas Keitt showed the lowest percentage protection (45.31\%). No direct correlation could be deduced between concentration of detected metabolites and the gastroprotective effect, so this activity might be attributed to synergistic effect between all secondary metabolites. Conclusions: This study spots the light on the great variation among the tested extracts; in addition, it provides effective techniques that pave the way for complete discrimination of these mango cultivars.

Key words: Chemometric analysis, gastroprotection, high-performance liquid chromatography, Mangifera indica L., mangiferin, random amplified polymorphic DNA
\end{abstract}

\section{SUMMARY}

- Eight mango cultivars were fully differentiated using RAPD-PCR. Chemical diversity was evidenced by Folin Ciocalteau and Aluminium chloride methods. Great variation was detected in different metabolites quantified using HPLC, and also in gastroprotective activity evaluated using Pylorus ligation model.

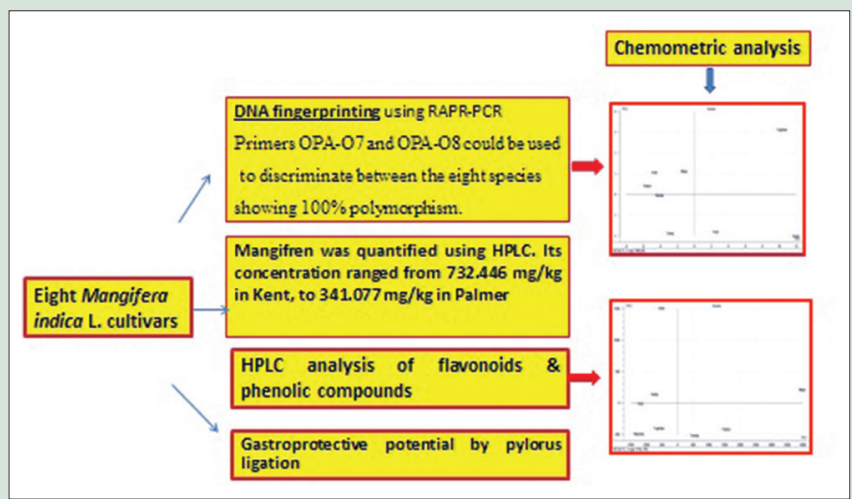

Abbreviations Used: RAPD: Random amplified polymorphic DNA; HPLC: High performance liquid chromatography; UV: Ultraviolet; PCA: Principle component analysis; PCR: Polymerase chain reaction.

Correspondence:

Dr. Rehab M. S. Ashour,

Department of Pharmacognosy, Faculty of Pharmacy, Cairo University, Kasr El-Ainy, Cairo 11562, Egypt.

E-mail: rehab.ashour@pharma.cu.edu.eg DOI: $10.4103 /$ pr.pr_99_19

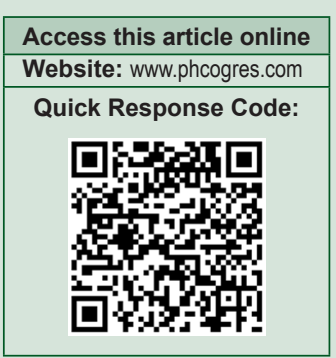

\section{INTRODUCTION}

Mangoes are members of genus Mangifera; it consists of about 70 genera, family Anacardiaceae. Historical records showed that its cultivation started in India more than 4000 years ago. ${ }^{[1]}$ Over one thousand mango cultivars are found around the world. ${ }^{[2]}$ It is usually cultivated for its fruit, which is considered to be as the "king of fruits" or "superfruit." [3] Mangifera indica L. is an important medicinal plant not only the fruit but also different parts of mango tree had various reported biological activities. ${ }^{[4]}$ Mangoes possess hypolipidemic, anticancer, antiparasitic, anti-HIV, antispasmodic, antidiarrheal, gastroprotective immunomodulation, antimicrobial, antifungal, antipyretic, anthelmintic and hepatoprotective activities. ${ }^{[5]}$ In Egypt, the immunostimulant, anticancer, and antimicrobial activities of the volatile oil of the peel of three mango cultivars (Zebdeya, Hindi, and Cobaneya) were investigated. ${ }^{[6]}$ They are considered a rich source of polyphenolics mainly mangiferin, phenolic acids, and flavonoids, found in all parts (pulp, peel, seed, bark, leaf, and flower) in various concentrations. The importance of polyphenolics arises primarily from their antioxidant capabilities, thus protection against many diseases. ${ }^{[7]}$

This is an open access journal, and articles are distributed under the terms of the Creative Commons Attribution-NonCommercial-ShareAlike 4.0 License, which allows others to remix, tweak, and build upon the work non-commercially, as long as appropriate credit is given and the new creations are licensed under the identical terms.

For reprints contact: reprints@medknow.com

Cite this article as: El-Hawary SS, Ashour RM, El-Gayed SH, Gad HA, Jaleel GA, El Gedaily RA. Genetic, chemical, and biological diversity in Mangifera indica L. cultivars. Phcog Res 2020;12:186-93. 
Peptic ulcer developed due to the imbalance among aggressive factors (acid, pepsin, and bile salts) and defensive factors (mucus, bicarbonate, prostaglandins, epithelial cell restoration, and blood flow) ${ }^{[8]}$ However, still the mechanism of the gastric ulcer is not well understood. ${ }^{[9,10]}$ Different therapeutic agents including proton-pump inhibitors, antihistaminic, and antacids are available for the treatment of this disorder, but the incidence of relapses, drug interactions, and side effects were reported. Thus, search for herbal drugs that decrease relapse and offer better protection is deemed of interest. ${ }^{[10]}$ Different models can be employed to induce peptic ulcer, for example, induction with ethanol, with nonsteroidal anti-inflammatory drugs, using stress, and by pylorus ligation. ${ }^{[11]}$

A previous study reported the potential gastroprotective effect of the aqueous decoction of mango leaves and stated that it may be attributed to the bioactive phenolic compounds present, representing $57.3 \%$ of the total extract. ${ }^{[12]}$ The aqueous decoction of mango flowers revealed to have significant gastroprotective and ulcer healing properties; meanwhile, using pylorus ligation, it significantly decreased the acid output, which proves its antisecretory effect leading to gastroprotection. ${ }^{[13]}$ Moreover, the stem bark methanolic extract of mango demonstrated significant dose-dependent ulceration inhibition. ${ }^{[14]}$

The eight mango cultivars under investigation, namely, Naaomy, Haidy, Fagrklan, Palmer, Keitt, Maya, Tommy atkins, and Kent, were misleading to be identified depending on their leaves' morphology.

The use of the appropriate cultivar is believed to be extremely important in herbal medicine to get the desired pharmacological action. This study aims to provide useful tools for the precise discrimination of these eight mango cultivars. The use of random amplified polymorphic DNA (RAPD) was reported to be an effective tool for the identification of plant cultivars, ${ }^{[15]}$ so it was the technique of choice to assess their genetic variability. In addition, quantification of the total polyphenolics and flavonoids was performed using Folin-Ciocalteu and aluminum chloride reagents, respectively. Further identification and quantification of different metabolites (mangiferin, polyphenolics, and flavonoids) in the tested extracts were achieved using high-performance liquid chromatography (HPLC)/ultraviolet (UV) detector.

Pylorus ligation-induced peptic ulcer or Shay's method was mainly employed to investigate and compare the effect of the tested extracts on gastric secretions and subsequently their possible gastroprotective potential. This model has the advantage of being capable of assessing the antisecretory and cytoprotective potential of drugs. ${ }^{[11]}$ Finally, application of principal component analysis (PCA), utilizing data obtained from both RAPD and HPLC, was employed to fully discriminate the mango cultivars under study.

\section{SUBJECTS AND METHODS}

\section{Standards and chemicals}

Ranitidine, aluminum chloride, and rutin were obtained from E-Merck, Darmstadt, Germany, whereas gallic acid from Sigma-Aldrich, USA. Folin-Ciocalteu was obtained from Loba-Chemie, India. All solvents were of the analytical grade and water was distilled. Standards of flavonoid aglycones and phenolic compounds, used in HPLC analysis, were obtained from different manufacturers and were of HPLC purity grade.

\section{Plant material}

The leaves of M. indica L. cultivars, namely, Naaomy, Haidy, Fagrklan, Palmer, Keitt, Maya, Tommy atkins, and Kent, were collected in July 2015 from the Ministry of Agriculture and Land Reclamation (Egypt). The plant was authenticated by Professor Dr. Gamal Haseeb, Fruit
Department Faculty of Agriculture, Cairo University. Voucher specimens numbered (2.4.2017 I-VIII) were placed at the Herbarium of the Faculty of Pharmacy (Pharmacognosy Department), Cairo University. DNA analysis was conducted in National Research Center, Dokki, Giza. HPLC analysis was performed at the Food Technology of Agriculture and Land Reclamation, Giza, Egypt.

\section{Genetic profiling (DNA fingerprint) Material for DNA}

$0.5 \mathrm{~g}$ of freeze-dried leaves ${ }^{[16]}$ of each of the eight mango cultivars was powdered in liquid nitrogen. Isolation of the DNA from the frozen plants was done using cetyltrimethylammonium bromide method. ${ }^{[17]}$ Ice-cold isopropanol was used to precipitate the nucleic acid.

\section{Polymerase chain reaction}

Amplifications were performed using 10 random arbitrary primers (OPA-01-10), synthesized by Operon biotechnologies Inc., Alameda, California, USA. ${ }^{[18]}$ Sequences of the primers are as follows: (5'-CAGGCCCTTC-3 ${ }^{`}$ ), (5`-TGCCGAGGTG-3`), (5`-AGTCA

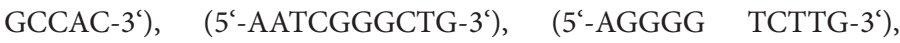
(5'-GGTCCCTGAC-3`), (5`-GAAACGGGTG-3`), (5`-GTGAC GTAGG$\left.3^{c}\right)$, (5'-GTGACGTAGG-3`), and (5'-GTGATCGCAG-3`), respectively.

Amplification was performed in $25 \mu \mathrm{l}$ reaction volume with the following reagents: $0.5 \mu \mathrm{l}$ of dNTPs $(10 \mathrm{mM}), 1.5 \mu \mathrm{lMgCl} 2(25 \mathrm{mM}), 5 \mu \mathrm{l}$ of $10 \times$ reaction buffer, $2.0 \mu \mathrm{l}$ of primer $(5 \mathrm{pmol}), 2.5 \mu \mathrm{l}$ of total genomic DNA $(20.4 \mathrm{ng} / \mu \mathrm{l}), 0.25 \mu \mathrm{l}$ of Taq polymerase $(10 / \mu \mathrm{l})$, and $14.75 \mu \mathrm{l}$ of sterile double-distilled $\mathrm{H}_{2} \mathrm{O}$.

\section{Polymerase chain reaction program and temperature profile}

DNA amplification was carried out in a Perkin Elmer 2400 thermal cycler, using the following program: for $3 \mathrm{~min}$, one cycle at $95^{\circ} \mathrm{C}$ (separation of initial strand), followed by $2 \mathrm{~min}, 45$ cycles at $92^{\circ} \mathrm{C}$ (for denaturation), $1 \mathrm{~min}$ at $37^{\circ} \mathrm{C}$ (for annealing), $2 \mathrm{~min}$ at $72^{\circ} \mathrm{C}$ (for elongation), $10 \mathrm{~min}$, 1 cycle at $72^{\circ} \mathrm{C}$ (for final extension), and finally $4^{\circ} \mathrm{C}$ (infinitive).

\section{Electrophoresis of polymerase chain reaction products}

Separation of amplified DNA fragments was done on $2 \%$ agarose gel plate. $10 \mu \mathrm{l}$ of each polymerase chain reaction (PCR) product was loaded onto the wells of the gels after being mixed with $2 \mu$ l loading buffer. The gels were run at 100 volts for about $30 \mathrm{~min}$.

\section{Visualization, scoring, and photography}

After electrophoresis, visualization was performed by staining with $0.2 \mu \mathrm{g} / \mathrm{ml}$ ethidium bromide solution and photographed using a gel documentation system under UV light. RAPD markers were scored as DNA fragments present in some lanes and absent in others.

\section{Spectrophotometric quantitative estimation of total polyphenolics}

Total polyphenols were determined colorimetry by Folin-Ciocalteu reagent. $0.5 \mathrm{~g}$ of dried leaves of each cultivar was homogenized, separately, in methanol using mortar and pestle, and the homogenate was centrifuged at $10,000 \mathrm{cycles} / \mathrm{min}$ for $20 \mathrm{~min}$. The supernatant was used for the estimation of total polyphenols. $2.5 \mathrm{ml}$ of Folin-Ciocalteu reagent was added to $0.5 \mathrm{ml}$ of each of methanolic extract and then $2.5 \mathrm{ml}$ of $7.5 \%$ sodium carbonate was added. The contents were incubated for $45 \mathrm{~min}$ at room temperature. The absorbance was measured at $710 \mathrm{~nm}$. Samples were prepared in triplicates and the mean value of absorbance was obtained. Blank was concurrently prepared. The same procedure was repeated for gallic acid as standard. Total polyphenolic content was calculated from the regression equation of the standard plot $\left(\mathrm{Y}=0.001 \mathrm{X}+0.0154, r^{2}=0.9993\right)$, where $\mathrm{Y}=$ absorbance, 
$\mathrm{X}=$ concentration, expressed as $\mathrm{g}$ gallic acid equivalent/100 $\mathrm{g}$ dried extract. ${ }^{[19]}$

\section{Spectrophotometric quantitative estimation of total flavonoids}

Aluminum chloride colorimetric method was used to determine flavonoid content. $1 \mathrm{ml}$ of sample extract was mixed with $3 \mathrm{ml}$ of methanol and $0.2 \mathrm{ml}$ of $10 \%$ aluminum chloride. $0.2 \mathrm{ml}$ of $1 \mathrm{M}$ potassium acetate and $5.6 \mathrm{ml}$ of distilled water and remains at room temperature for $30 \mathrm{~min}$. The absorbance was measured at $420 \mathrm{~nm}$. Rutin was used as standard $(1 \mathrm{mg} / \mathrm{ml})$. Flavonoid content was calculated from the regression equation of the standard plot $\left(\mathrm{Y}=0.001 \mathrm{X}+0.0286, r^{2}=0.991\right)$ expressed as g rutin equivalent $/ 100 \mathrm{~g}$ of dried extract. ${ }^{[20]}$

\section{Material for high-performance liquid chromatography \\ Preparation of plant extracts for high-performance liquid chromatography and biological study}

$500 \mathrm{~g}$ of dried leaves of each of the eight cultivars, namely, Naaomy, Haidy, Fagrklan, Palmer, Keitt, Maya, Tommy atkins, and Kent, was macerated in $70 \%$ alcohol at room temperature. The resulting extracts were concentrated under vacuum, to yield $25 \mathrm{~g}, 40 \mathrm{~g}, 50 \mathrm{~g}, 32 \mathrm{~g}, 46 \mathrm{~g}$, $30 \mathrm{~g}, 41 \mathrm{~g}$, and $22 \mathrm{~g}$, respectively.

\section{Sample preparation for high-performance liquid chromatography}

Extraction, hydrolysis, and identification of flavonoids and polyphenolic compounds were performed according to Mattila et al. and Goupy et al. ${ }^{[21,22]}$

Standards for phenolic components of the samples were prepared in methanol as $50-600 \mu \mathrm{g} / \mathrm{ml}$ solutions. Quantification was based on retention times comparison and measuring the peak areas of both samples and standards using the external standard method. All experiments were made in triplicates and the average was taken.

\section{Chromatographic conditions for high-performance liquid chromatography analysis of phenolic compounds}

Detailed conditions are attached in Supplementary File S-A.

\section{Chromatographic conditions for high-performance liquid} chromatography analysis of flavonoids and mangiferin

Detailed conditions are attached in Supplementary File S-B.

\section{Gastroprotective activity Animals}

Adult male Swiss albino mice (30-40 g) and male Wistar albino rats, weighing 150-170 g, were obtained from the National Research Centre animal house in Dokki, Giza, Egypt. The animals were housed in an air-conditioned room at $22^{\circ} \mathrm{C} \pm 3^{\circ} \mathrm{C}$ and $55 \% \pm 5 \%$ humidity, in metal cages. Standard laboratory diet was provided and water ad libitum under standard conditions of $12 \mathrm{~h}$ dark/12 h light. Experiments were conducted in the period between 9:00 and 15:00 h. Procedures of all experiments were performed according to the laboratory animals care and use guide and approved by the National Research Centre ethics committee, registration number (Mp2536). They also followed the recommendations provided by the Health Guide of National Institutes for Care and Use of Laboratory Animals (Publication No. 85-23, revised 1985).

Acute toxicity $\left(L D_{50}\right)$ study

The median lethal dose $\left(\mathrm{LD}_{50}\right)$ for each mango cultivar extract was determined orally in mice adopting Lorke's method ${ }^{[23]}$ with modifications. Detailed procedures are attached in Supplementary File S-C.

\section{Experimental procedure}

Pylorus ligation-induced ulceration

Pylorus ligation was done as described by Shay ${ }^{[24]}$ with slight modifications. Detailed procedures are attached in Supplementary File S-D1.

\section{Determination of gastric wall mucus content}

The mucus of gastric wall was estimated according to Corne et al. (1974). ${ }^{[25]}$ Detailed procedures are attached in Supplementary File S-D2.

\section{Determination of peptic activity}

Detailed procedures are attached in Supplementary File S-D3.

\section{Determination of gastric mucin content}

This was achieved as described by Winzler. ${ }^{[26]}$ Detailed procedures are attached in Supplementary File S-D4.

\section{Histopathology}

The samples of the stomach from different groups were preserved using $10 \%$ buffered formalin. They were processed for paraffin block preparation. Sections of approximately $5 \mathrm{~mm}$ thickness were cut. Hematoxylin and eosin was used for staining. Examination under a microscope for histopathological changes such as degeneration, erosion, edematous appearance, hemorrhage, and necrosis was performed.

\section{Statistical and chemometric analysis}

One-way analysis of variance was used for results analysis, followed by Tukey's post hoc test and expressed as mean \pm standard error of the mean. The statistical software used to analyze the data was SPSS version 15 (IBM corp., Armonk, N.Y., USA). The obtained results were considered significant when $P<0.05$. PCA was performed employing Unscrambler 9.7 (CAMO SA, Oslo, Norway).

\section{RESULTS}

\section{Genetic profiling (DNA fingerprint)}

RAPD analysis of the eight mango cultivars was performed using ten decamer primers, from OPA-01 to OPA-10, respectively. The banding profiles produced are recorded in Tables 1 and 2. The ten DNA primers generated a total of 479 fragments in all eight species, where 94 fragments were generated in cultivar Haidy and 40 fragments in cultivar Palmer.

Monomorphic bands (common in all species) were 12 bands, whereas 375 fragments were polymorphic (present in at least one species and absent in others), representing a total level of polymorphism of $72.28 \%$. The highest percentage of polymorphism $100 \%$ was observed with primers A-O7 and A-O8, whereas the least percentage $37.25 \%$ was obtained with primer A-O4.

\section{Spectrophotometric estimation of total polyphenolics}

Relatively high phenolic content was observed in Fagrklan, Palmer, and Haidy cultivars $(29.54,28.66$, and 27.25 g gallic acid equivalent/100 g extract, respectively), whereas Kent, Keitt, Naaomy, and Maya cultivars showed lower phenolic content (24.63-22.68 g gallic acid equivalent/100 g extract). Meanwhile, Tommy atkins had the lowest phenolic content. The results are shown in Table 3.

\section{Spectrophotometric estimation of total flavonoids}

Great variation in flavonoid content was observed in the tested cultivars. The highest concentration was recorded in Fagrklan (93.40), whereas the 
Table 1: Total number of random amplified polymorphic DNA-polymerase chain reaction fragments

\begin{tabular}{|c|c|c|c|c|c|c|c|c|c|}
\hline Primers & Naaomy & Haidy & Fagrklan & Palmer & Keitt & Maya & Tommy & Kent & Total \\
\hline OPA-01 & 5 & 10 & 7 & 5 & 5 & 7 & 5 & 7 & 51 \\
\hline OPA-02 & 4 & 7 & 8 & 4 & 5 & 6 & 4 & 5 & 43 \\
\hline OPA-03 & 4 & 8 & 10 & 4 & 4 & 6 & 4 & 6 & 46 \\
\hline OPA-04 & 5 & 10 & 12 & 4 & 4 & 6 & 4 & 6 & 51 \\
\hline OPA-05 & 4 & 9 & 8 & 4 & 5 & 6 & 5 & 5 & 46 \\
\hline OPA-06 & 4 & 8 & 9 & 4 & 6 & 4 & 4 & 8 & 47 \\
\hline OPA-07 & 4 & 11 & 9 & 3 & 3 & 4 & 6 & 7 & 47 \\
\hline OPA- 08 & 4 & 10 & 9 & 4 & 4 & 4 & 5 & 8 & 48 \\
\hline OPA-09 & 5 & 12 & 9 & 4 & 4 & 6 & 5 & 6 & 51 \\
\hline OPA-10 & 5 & 9 & 7 & 4 & 4 & 6 & 6 & 8 & 49 \\
\hline Total & 44 & 94 & 88 & 40 & 44 & 55 & 48 & 66 & 479 \\
\hline
\end{tabular}

OPA: Operon Primers A-series

Table 2: Monomorphic and polymorphic bands generated by 10 primers

\begin{tabular}{lccc}
\hline Primers & $\begin{array}{c}\text { Monomorphic } \\
\text { bands }\end{array}$ & $\begin{array}{c}\text { Polymorphic } \\
\text { bands }\end{array}$ & $\begin{array}{c}\text { Percentage } \\
\text { polymorphism }\end{array}$ \\
\hline OPA-01 & 1 & 43 & 84.31 \\
OPA-02 & 1 & 35 & 81.39 \\
OPA-03 & 1 & 38 & 82.60 \\
OPA-04 & 3 & 19 & 37.25 \\
OPA-05 & 2 & 30 & 65.21 \\
OPA-06 & 1 & 39 & 82.97 \\
OPA-07 & 0 & 47 & 100 \\
OPA-08 & 0 & 48 & 100 \\
OPA-09 & 1 & 43 & 84.31 \\
OPA-10 & 2 & 33 & 67.34 \\
Total & 12 & 375 & 78.28 \\
\hline
\end{tabular}

Percentage polymorphism: Polymorphic bands/total bands of each primer. OPA: Operon Primers A-series

Table 3: Spectrophotometric quantitative estimation of polyphenolics and flavonoids

\begin{tabular}{lcc}
\hline $\begin{array}{l}\text { Mango } \\
\text { cultivars }\end{array}$ & $\begin{array}{c}\text { Total phenolics (g Gallic } \\
\text { acid equivalent/100 g } \\
\text { extract) }\end{array}$ & $\begin{array}{c}\text { Total flavonoids } \\
\text { (g rutin equivalent/ } \\
\text { 100 g extract) }\end{array}$ \\
\hline Naaomy & 22.82 & 47.20 \\
Haidy & 27.25 & 56.63 \\
Fagrklan & 29.54 & 93.40 \\
Palmer & 28.66 & 42.62 \\
Keitt & 22.88 & 71.36 \\
Maya & 22.68 & 72.49 \\
Tommy atkins & 14.58 & 22.49 \\
Kent & 24.63 & 63.45 \\
\hline
\end{tabular}

lowest was in Tommy atkins (22.49) calculated as g rutin equivalent/100 g extract. The results are shown in Table 3.

\section{High-performance liquid chromatography quantification of mangiferin}

Mangiferin concentration was high in Kent $(732.446 \mathrm{mg} / \mathrm{kg})$, followed by Keitt and Naaomy (673.801 and $641.261 \mathrm{mg} / \mathrm{kg}$, respectively) and then by Fagrklan and Haidy (575.921 and $531 \mathrm{mg} / \mathrm{kg}$, respectively), whereas relatively lower mangiferin concentrations were observed in Maya, Tommy, and Palmer (488.114, 420.968, and $341.077 \mathrm{mg} / \mathrm{kg}$, respectively).

\section{High-performance liquid chromatography quantification of polyphenolics}

HPLC analysis led to the identification of 18 phenolic compounds in the leaves of the eight mango cultivars under study. The results are shown in Table 4.
Maya showed high content of ethyl vanillic acid ( $5742.22 \mathrm{mg} / \mathrm{kg})$, followed by Palmer and Tommy (3233.38 and $2306.37 \mathrm{mg} / \mathrm{kg}$, respectively). Caffeic acid was detected in considerably high amounts relative to other phenolic compounds in all tested mango cultivars with concentration ranging from $2266.66 \mathrm{mg} / \mathrm{kg}$ in Keitt to $1106.94 \mathrm{mg} / \mathrm{kg}$ in Naaomy. Meanwhile, vanillic acid concentration was 1342.15 and $1224.55 \mathrm{mg} / \mathrm{kg}$ in Tommy and Naaomy, respectively. Catechol was detected in its highest concentration in Kent, followed by Haidy (1788.34 and $588.55 \mathrm{mg} / \mathrm{kg}$, respectively).

\section{High-performance liquid chromatography quantification of flavonoids}

A total of nine flavonoids were identified and quantified in the tested mango cultivars. The results are shown in Table 5.

Hesperidin was the main flavonoid detected in all cultivars with concentration ranging from $20.482 \mathrm{mg} / \mathrm{kg}$ in Tommy to $3.068 \mathrm{mg} / \mathrm{kg}$ in Fagrklan. Meanwhile, rutin was observed at concentration of 6.997, 4.610, and $3.042 \mathrm{mg} / \mathrm{kg}$ in Palmer, Haidy, and Kent, respectively.

\section{Pharmacological assessment Acute toxicity tests}

Both phases (first and second) of acute toxicity study showed no notable toxicity signs in mice.

\section{Antisecretory gastroprotective activity}

Macroscopic examination (ulcer number, ulcer index, and percentage protection)

Stomachs of ulcer control rats (rats with pyloric ligation) appeared with clear ulceration in their glandular area in comparison with normal control rats. Significant reduction in ulcer index with $67 \%$ protection was established upon pretreatment with ranitidine. Pretreatment with tested extracts significantly reduced ulcer index. Kent showed the highest protection (65\%), followed by Haidy and Fagrklan (64\%), Naaomy (62\%), Tommy atkins (53\%), Palmer (51\%), Maya (50\%), and Keitt (45\%) [Table 6].

\section{Effects of extracts on gastric juice parameters and on gastric wall mucus content}

Pretreatment with all tested extracts significantly decreased total acidity, acid output, and peptic activity as compared to ulcer control group $(P<0.05)$ and also significantly increased gastric wall mucus production and mucin content $(P<0.05)$ as compared to the control group. Fagrklan showed the most potent effect mimic to ranitidine standard [Table 7].

\section{Histopathological study}

Photomicrography of stomach subjected to pylorus ligation revealed 
Table 4: High-pressure liquid chromatography quantification of polyphenolics

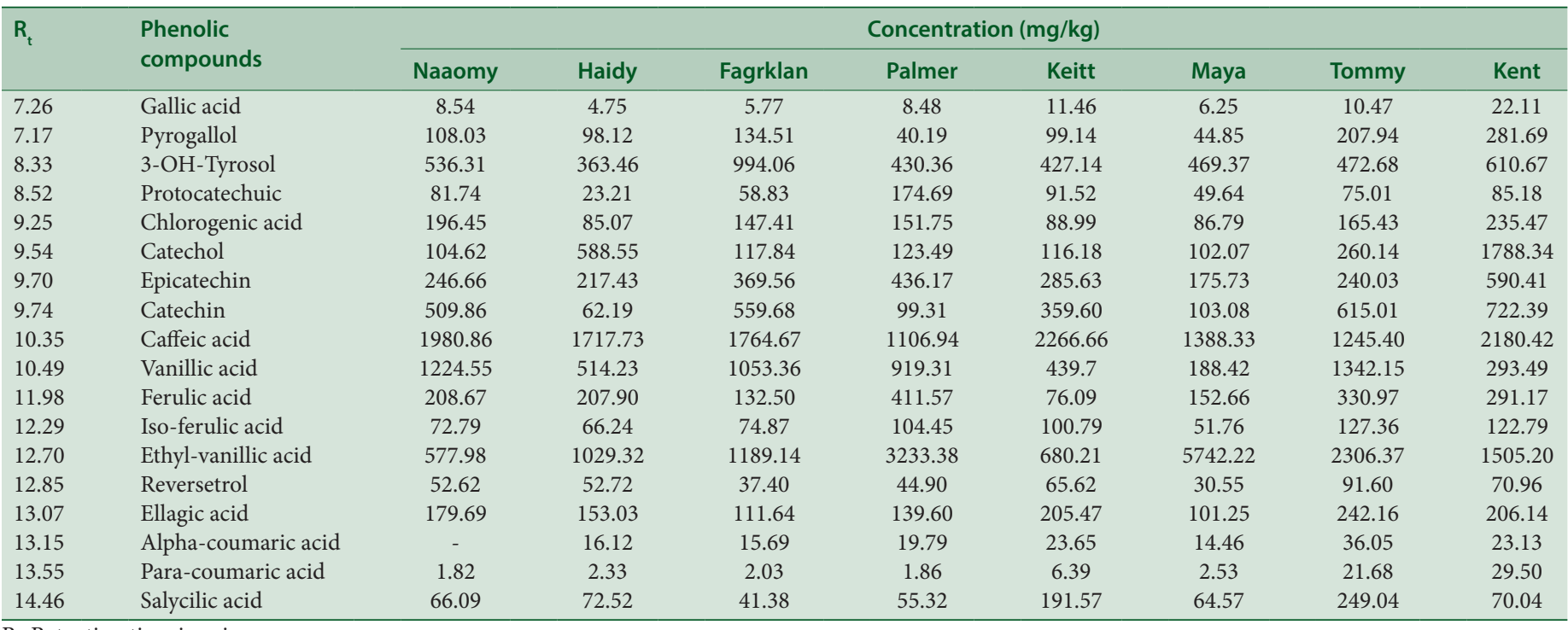

$\mathrm{R}_{\mathrm{t}}$ : Retention time in $\min$

Table 5: High-pressure liquid chromatography quantification of flavonoids

\begin{tabular}{|c|c|c|c|c|c|c|c|c|c|}
\hline \multirow[t]{2}{*}{$R_{t}$} & \multirow[t]{2}{*}{ Flavonoids } & \multicolumn{8}{|c|}{ Concentration (mg/kg) } \\
\hline & & Naaomy & Haidy & Fagrklan & Palmer & Keitt & Maya & Tommy & Kent \\
\hline 12.287 & Naringin & 0.515 & 0.419 & 0.634 & 0.626 & 0.499 & 0.376 & 1.287 & 1.352 \\
\hline 12.441 & Rutin & 0.545 & 4.610 & 0.679 & 6.997 & 1.47 & 2.482 & 0.671 & 3.042 \\
\hline 12.571 & Hesperidin & 14.484 & 12.692 & 3.068 & 5.907 & 19.487 & 9.075 & 20.482 & 7.268 \\
\hline 13.467 & Quercetrin & 0.453 & 0.472 & 0.429 & 0.610 & 0.338 & 0.396 & 0.276 & 0.438 \\
\hline 14.978 & Quercetin & 0.034 & 0.040 & 0.095 & 0.064 & 0.141 & 0.066 & 0.09 & 0.088 \\
\hline 15.798 & Narengenin & 0.001 & 0.008 & 0.001 & 0.006 & 0.006 & 0.003 & 0.005 & 0.006 \\
\hline 16.120 & Hesperitin & 0.004 & 0.015 & 0.010 & 0.004 & 0.279 & 0.026 & 0.266 & 0.060 \\
\hline 16.257 & Kampferol & 0.035 & 0.104 & 0.076 & 0.022 & 0.02 & 0.008 & 0.026 & 0.022 \\
\hline 16.551 & Apigenin & 0.005 & 0.060 & 0.165 & 0.033 & 0.055 & 0.025 & 0.059 & 0.043 \\
\hline
\end{tabular}

$\mathrm{R}_{\mathrm{t}}$ : Retention time in min

Table 6: Ulcer index and percentage protection of the eight tested mango cultivars

\begin{tabular}{lcc}
\hline Groups & Ulcer index & Percentage protection \\
\hline Control (pyloric ligated) & $6.4 \pm 0.7$ & - \\
Ranitidine $(100 \mathrm{mg} / \mathrm{kg})$ & $2.1 \pm 0.04^{*}$ & 67.18 \\
Mangifera indica cultivars & & \\
Naaomy & $2.4 \pm 0.01^{*}$ & 62.50 \\
Haidy & $2.3 \pm 0.20^{*}$ & 64.06 \\
Fagrklan & $2.3 \pm 0.07^{*}$ & 64.06 \\
Palmer & $3.1 \pm 0.25^{*}$ & 51.56 \\
Keitt & $3.5 \pm 0.31^{*}$ & 45.31 \\
Maya & $3.2 \pm 0.28^{*}$ & 50.00 \\
Tommy atkins & $3.0 \pm 0.09^{*}$ & 53.12 \\
Kent & $2.2 \pm 0.21^{*}$ & 65.62 \\
\hline
\end{tabular}

Each value represents the mean of 5 rats \pm SE. * Significantly different from control pyloric ligated group at $P<0.05$. SE: Standard error

the lack of secreting lining of the epithelium as well as congested vascular spaces and moderate edema [Figure 1a]. On the other hand, ranitidine-treated rats showed that the secreting layer of epithelium was restoring its activity and continuity, along with decreased edemas and congestion at the submucosal level [Figure 1b].

The highest degree of healing and least remaining pathology was shown in a descending order starting from Fagrklan, Haidy, Maya, and Kent cultivars as shown in Figure $1 \mathrm{~d}, \mathrm{e}, \mathrm{h}$ and $\mathrm{j}$, respectively. The covering mucosa was intact in the four groups, whereas tissue edema, areas of hemorrhage, and inflammatory cellular infiltrate were increasing from Fagrklan, to Haidy, and Maya cultivars, being mostly expressed in Kent cultivar. On the other hand, Naaomy, Keitt, Palmer, and Tommy atkins cultivars had a similar presentation of slugged surface epithelium with massive tissue edema, inflammatory cellular infiltrate, and showing mucosal ulceration with submucosal edema and hemorrhage as represented in Figure 1c, f, g and i, respectively.

\section{Chemometric analysis}

This was done by applying PCA, utilizing the ten primers in the eight cultivars studied, as shown in Figure 2. PCA score plot could successfully discriminate and segregate different mango cultivars, where the score plot explained about $92 \%$ of the variance in 180-dimensional space using only the first two components (the first PC accounts for $86 \%$ of the total variance followed by the second PC with 6\%). As obvious, samples Haidy, Kent, and Fagrklan were positioned on the right side of the plot (positive PC1) and they were completely segregated confirming their genetic diversity. However, all other samples were placed on the left side (negative PC1) with sample Tommy on the lower quadrant away from all other samples. Samples Keitt, Palmer, Naaomy, and Maya were very close to each other, indicating their genetic similarity. In addition, the primers having the greatest influence on the scores plot were detected from the loading plot, as shown in Figure 3, where primers A-O4, A-O7, and $\mathrm{A}-\mathrm{O} 8$ were the main markers responsible for the segregation of samples Fragklan, Haidy, and Kent, respectively. 
Table 7: Gastroprotective activity on pylorus ligation induced ulcer in rats

\begin{tabular}{|c|c|c|c|c|c|c|}
\hline Groups & $\begin{array}{l}\text { Gastric juice } \\
\text { volume (ml) }\end{array}$ & $\begin{array}{l}\text { Total acidity } \\
(\mathrm{mEq} / \mathrm{l})\end{array}$ & $\begin{array}{l}\text { Acid output } \\
\text { ( } \mu \mathrm{Eq} / 4 \mathrm{~h})\end{array}$ & $\begin{array}{c}\text { Gastric wall } \\
\text { mucus (alcian } \\
\text { blue } \mu \mathrm{g} / \mathrm{g} \text { tissue) }\end{array}$ & $\begin{array}{c}\text { Peptic activity } \\
\text { ( } \mu \mathrm{M} \text { tyrosine/ } \\
\mathrm{ml} / \mathrm{min} \text { ) }\end{array}$ & $\begin{array}{c}\text { Mucin } \\
\text { content (mg } \\
\text { hexose } / \mathrm{ml} \text { ) }\end{array}$ \\
\hline Control (pyloric ligated) & $3.7 \pm 0.14$ & $157 \pm 9.25$ & $144.4 \pm 11.9$ & $75.1 \pm 6.16$ & $143.5 \pm 6.5$ & $0.67 \pm 0.04$ \\
\hline Ranitidine (100 mg/kg) & $3.4 \pm 0.25$ & $47.0 \pm 4.1^{\star}$ & $52.4 \pm 4.4^{*}$ & $183.0 \pm 9.8^{*}$ & $89.4 \pm 5.25^{\star}$ & $1.24 \pm 0.06^{*}$ \\
\hline \multicolumn{7}{|c|}{ Mangifera indica cultivars $(200 \mathrm{mg} / \mathrm{kg})$} \\
\hline Naaomy & $3.1 \pm 3.1$ & $77.6 \pm 4.3^{\star}$ & $61.3 \pm 5.3^{*}$ & $164.0 \pm 6.8^{\star}$ & $106.3 \pm 8.4^{*}$ & $1.12 \pm 0.02^{\star}$ \\
\hline Haidy & $3.0 \pm 0.35$ & $60.0 \pm 4.8^{*}$ & $46.0 \pm 4.6^{*}$ & $185.0 \pm 10.7^{*}$ & $116.5 \pm 4.9^{*}$ & $1.03 \pm 0.02^{*}$ \\
\hline Fagrklan & $2.8 \pm 0.27$ & $50.0 \pm 4.4^{*}$ & $36.7 \pm 3.1^{*}$ & $198.0 \pm 9.6^{*}$ & $101.9 \pm 2.3^{*}$ & $1.18 \pm 0.03^{*}$ \\
\hline Palmer & $4.2 \pm 0.4$ & $78.0 \pm 4.9^{*}$ & $82 \pm 7.7^{*}$ & $143.0 \pm 10.7^{*}$ & $116.9 \pm 4.1^{*}$ & $1.02 \pm 0.02^{*}$ \\
\hline Keitt & $4.1 \pm 0.7$ & $49.0 \pm 4.5^{*}$ & $50.2 \pm 4.3^{*}$ & $153.0 \pm 10.6^{*}$ & $107.2 \pm 4.4^{*}$ & $1.11 \pm 0.01^{*}$ \\
\hline Maya & $3.8 \pm 3.7$ & $49.0 \pm 4.8^{*}$ & $46.2 \pm 3.6^{*}$ & $176.0 \pm 11.5^{*}$ & $115.1 \pm 4.0^{*}$ & $1.06 \pm 0.03^{*}$ \\
\hline Tommy atkins & $4.3 \pm 0.25$ & $84.0 \pm 7.4^{*}$ & $84.4 \pm 3.7^{\star}$ & $135.0 \pm 11.9^{*}$ & $119.3 \pm 3.5^{*}$ & $0.98 \pm 0.01^{*}$ \\
\hline Kent & $5.0 \pm 0.55$ & $49.0 \pm 5.1^{\star}$ & $60.0 \pm 6.1^{*}$ & $172.0 \pm 8.5^{\star}$ & $96.5 \pm 4.0^{*}$ & $1.21 \pm 0.04^{*}$ \\
\hline
\end{tabular}

Each value represents the mean of 5 rats \pm SE. ${ }^{*}$ Significantly different from control pyloric ligated group at $P<0.05$. SE: Standard error

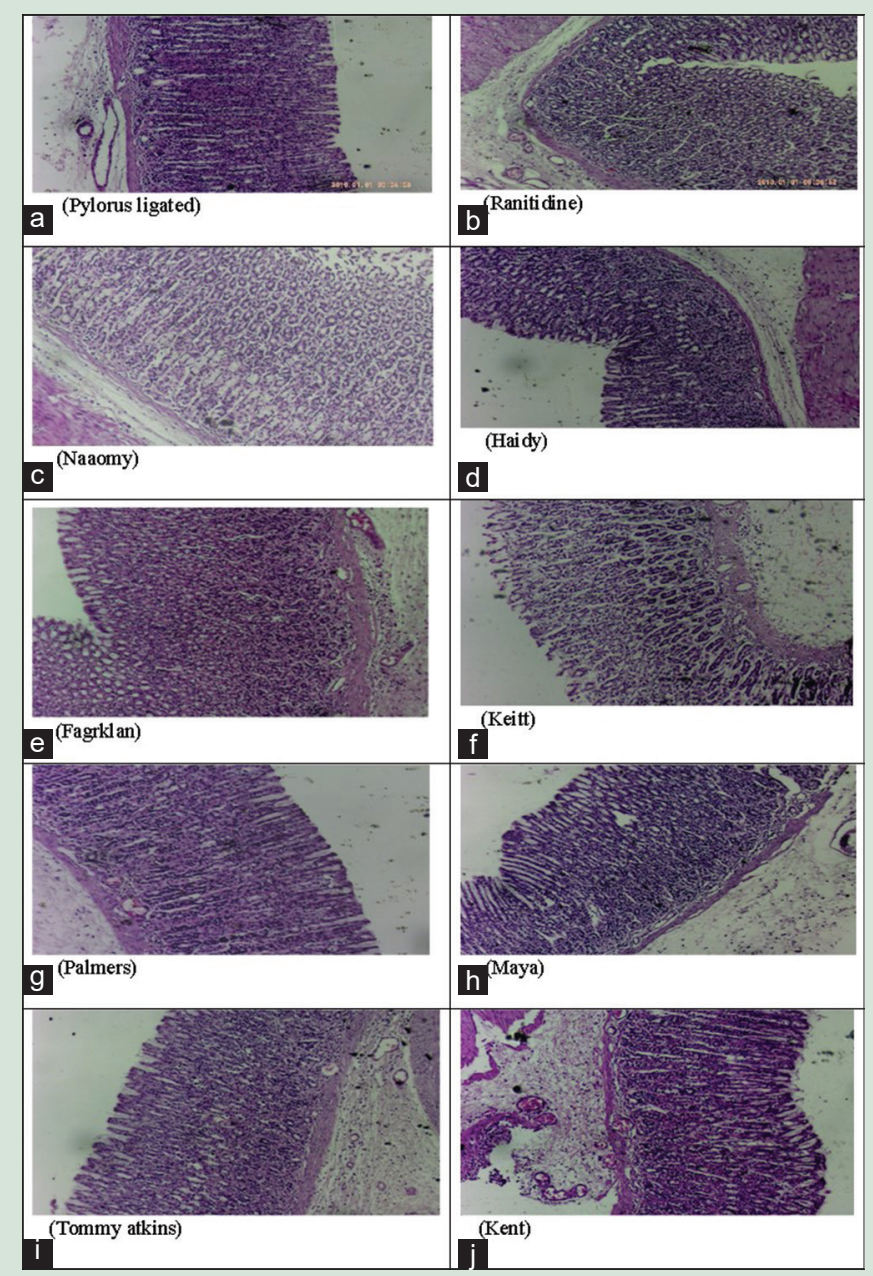

Figure 1: Photomicrographs of stomach sections of different treatment groups stained by $\mathrm{H}$ and E. (a) Pylorus ligated, (b) Ranitidine, (c) Naamoy, (d) Haidy, (e) Fagrklan, (f) Keitt, (g) Palmers, (h) Maya, (i) Tommy atkins, (j) Kent

To estimate the discriminative ability of the identified compounds by HPLC, PCA analysis was employed as a data reduction technique using the relative peak areas of the identified components as input data, to generate a visual plot for qualitative assessment on the similarity and dissimilarity of the tested samples. PCA score plot Figure 4 resulted in two orthogonal PCs, which explained about $93 \%$ of the variance in 180-dimensional space using only the first two components (the first

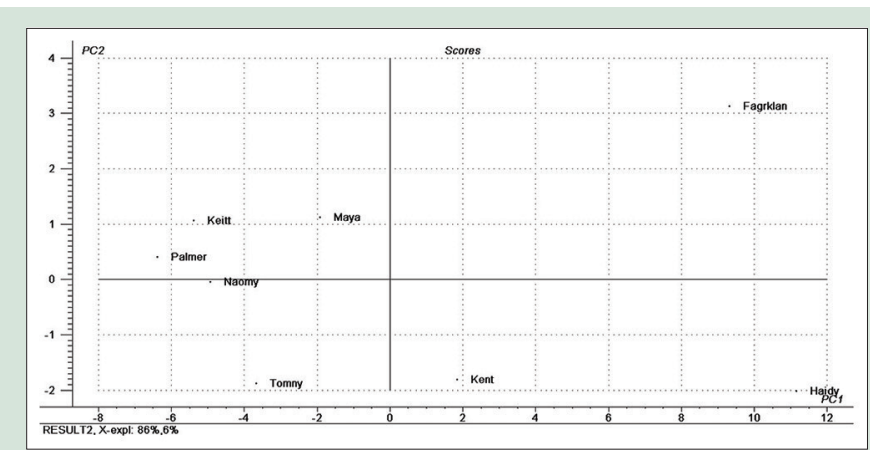

Figure 2: Principal component analysis score plot utilizing ten primers of eight mango cultivars

PC accounts for $81 \%$ of the total variance followed by the second PC with 12\%). From the scatter points, different mango cultivars could be completely discriminated. On the right side of the plot, Tommy and Palmer are positioned (positive PC1 values). However, samples (Haidy, Keitt, Naaomy, and Fagrklan) were placed on the far left side (negative PC1 values) without any overlap among samples. Haidy and Keitt samples were separated from Naaomy and Fagrklan in relation to their position regarding PC2. Two samples Maya and Kent were detected as outliers, which investigated their clear compositional differences among all tested samples. The specific peaks, which had the most influence on the separation among different mango cultivars, were found out with the help of PCA loading plot. The loading plot of PCA [Figure 5] indicated that catechol, caffeic acid, vanillic acid, and ethyl vanillic may have more influence on the discrimination of different cultivars. These variables could be used as chemical markers in HPLC quality control of different mango cultivars in the future.

\section{DISCUSSION}

The current study aimed to fully discriminate the leaves of eight tested mango cultivars based on genetic, chemical, and biological features. Furthermore, chemometric analysis was applied to provide strict evidences about relationships between the studied species. This discrimination is believed to be extremely valuable to prevent unfortunate misleading use of one cultivar instead of another, which might lead to altered pharmacological effect than expected. The choice of the leaves was decided considering the beneficial use of mango by-products in health and industry.

DNA-based tools are an evolving measure for authentication and identification of medicinal plants. ${ }^{[27]}$ The results of RAPD-PCR indicated 


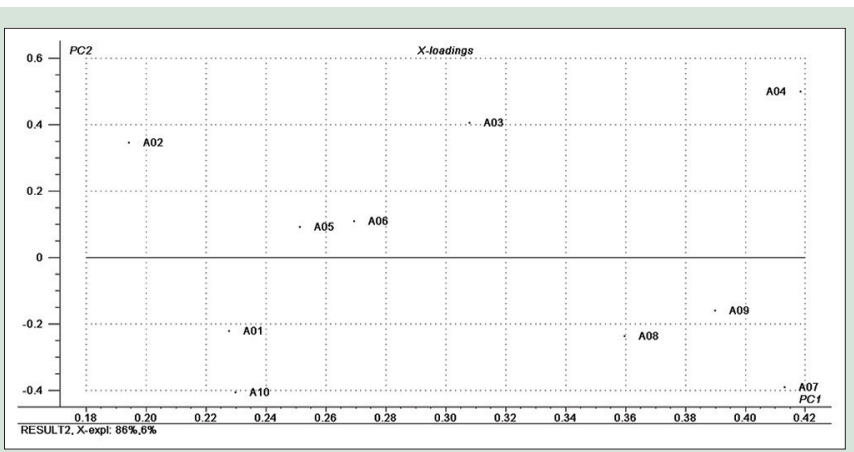

Figure 3: Principal component analysis loading plot utilizing ten primers of eight mango cultivars

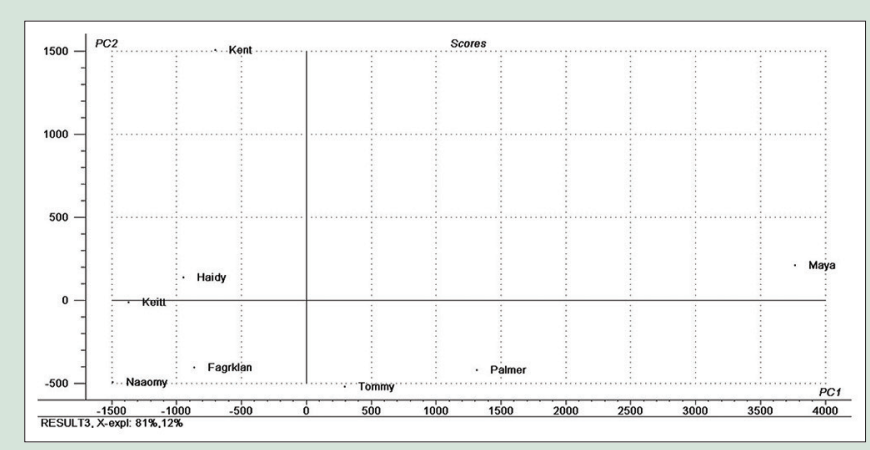

Figure 4: Principal component analysis score plot of relative peak areas of total compounds identified by high-performance liquid chromatography in eight mango cultivars (average of 3 replicates)

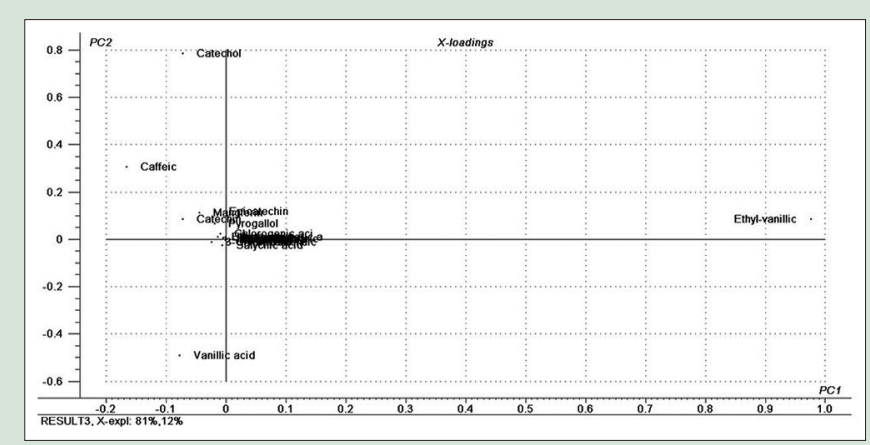

Figure 5: Principal component analysis loading plot of relative peak areas of total compounds identified by high-performance liquid chromatography in eight mango cultivars (average of 3 replicates)

high diversity among the cultivars under study. Primers A-O7 and A-O8 (100\% polymorphism) can be effectively used to differentiate between the eight mango cultivars. Moreover, chemometric analysis was able to discriminate the different cultivars based on the primers used, where primers $\mathrm{A}-\mathrm{O} 4, \mathrm{~A}-\mathrm{O} 7$, and $\mathrm{A}-\mathrm{O} 8$ are the main markers responsible for the segregation of samples Fragklan, Haidy, and Kent, respectively.

Polyphenolics, flavonoids, and mangiferin have been frequently reported not only in the edible part of mango fruits but also in the seed, skin, and leaves. ${ }^{[28]}$ Upon estimation of the total phenolic content, Fagrklan showed almost double the phenolic content (29.54 g gallic acid equivalent/100 g extract) compared to Tommy atkins (14.58 g gallic acid equivalent/100 g extract). A previous study from India indicated the phenolic content of mango leaf to be $49.76 \mathrm{~g} / 100 \mathrm{~g}$ gallic acid equivalent. ${ }^{[29]}$ Furthermore, the total flavonoid content was highest in Fagrklan (93.40 g rutin equivalent/100 g extract), whereas Tommy atkins showed remarkable almost 4 -fold decrease (22.49 g rutin equivalent/100 g extract). These findings with profound diversity in the quantitative analysis drove our interest to deeply explore the chemical composition of the eight mango cultivars, to get a more comprehensive insight about their chemical constituents and their relation to the gastroprotective and antisecretory effect using pylorus ligation model.

HPLC quantification of different metabolites (mangiferin, polyphenolics, and flavonoids) generally revealed great variation in the concentration of these metabolites among the tested cultivars. This compositional difference may be attributed to environmental and biological factors. ${ }^{[30]}$ Mangiferin concentration was $732.446 \mathrm{mg} / \mathrm{kg}$ in Kent, whereas in Palmer, it dropped more than 2-fold to $341.077 \mathrm{mg} / \mathrm{kg}$. Mangiferin (C-glycosyl xanthone) is reported to be the main phenolic constituent in mango; ${ }^{[31]}$ it can be obtained from leaves, fruits, bark, and roots. ${ }^{[28]}$ This variation detected in mangiferin concentration is in accordance with that previously reported on 11 mango pulp cultivars, in which it was only detected in five of them with variable concentrations (0.032$3.20 \mathrm{mg} / 100 \mathrm{~g})$. $^{[28]}$

In spite of the fact that Kent showed the highest mangiferin concentration as well as the highest percentage of gastric protection, the rest of the results showed no direct correlation between this constituent concentration and the activity under study. This was clearly evidenced by the percentage protection of Keitt cultivar that took the second place in mangiferin concentration among the tested samples, yet it revealed the lowest percentage protection (45.31\%). Polyphenolics, for example, caffeic acid and catechol as well as flavonoids, play an important role as protective agents against ulcer through their cytoprotective, antisecretory, and antioxidant effects. ${ }^{[32]}$

Although, in all eight tested cultivars, caffeic acid, ethyl vanillic acid, and vanillic acid were the most abundant phenolic acids identified. caffeic acid was found in highest concentration in Keitt (2266.66 mg/ $\mathrm{kg}$ ), while maximum concentration of ethyl vanillic acid was observed in Maya $(5742.22 \mathrm{mg} / \mathrm{kg})$, and vanillic acid concentration was optimum in Tommy (1342.15 mg/kg).

It was remarkable that Kent showed relatively high concentrations of catechol (1788.34 mg/kg), followed by Haidy $(588.55 \mathrm{mg} / \mathrm{kg})$, compared to other cultivars under study. This great variation in different constituents' concentration is also seen concerning the detected flavonoids, for example, hesperidin concentration, which varied from 20.48 in Tommy atkins to 3.07 in Fagrklan. No direct relation was observed between any of the detected phenolics or flavonoid concentrations and the obtained protection against ulcer.

Finally, it could be concluded that the gastroprotective effect for the tested cultivars might be due to synergistic effect of all secondary metabolites present in the leaves of these cultivars rather than to a single component. By utilizing the data obtained from HPLC in combination with chemometrics, the results showed the successful application of PCA in the segregation of different mango cultivars based on the identified peak areas, which confirmed the diversity in their composition quantitatively. PCA loading plot investigated the main chemical markers responsible for cultivar discrimination, which are identified as catechol, caffeic acid, vanillic acid, and ethyl vanillic acid.

This great variation spots the importance of the precise recognition, of which cultivar can be used medicinally to prevent any health hazards. Strict identification of the cultivar used should be adopted to get the desired pharmacological action. 


\section{CONCLUSIONS}

All tested $M$. indica cultivars showed great variation in secondary metabolites. No correlation was observed between a specific metabolite and the gastroprotective activity. Full differentiation using DNA fingerprinting, chemical analysis, and PCA was successfully achieved. This study provided the most precise information to set strict boundaries between the eight mango cultivars under study.

\section{Financial support and sponsorship}

Nil.

\section{Conflicts of interest}

There are no conflicts of interest.

\section{REFERENCES}

1. Mukherjee S, Litz R. The Mango: Botany, Production and Uses. CAB International, Wallingford; 1997.

2. Bally IS. Mangifera indica (mango), ver. 3.1," in Species Profiles for Pacific Island Agroforestry, C. R. Elevitch, Ed., Permanent Agriculture Resources (PAR), Holualoa, Hawaii, USA, 2006.

3. Noratto GD, Bertoldi MC, Krenek K, Talcott ST, Stringheta PC, Mertens-Talcott SU. Anticarcinogenic effects of polyphenolics from mango (Mangifera indica) varieties. J Agric Food Chem 2010;58:4104-12.

4. Ghuniyal J. Ethanomedical, chemical, pharmacological, toxicological properties of Mangifera indica: A review. Int J Pharma Res Rev 2015;4:51-64.

5. Parvez GM. Pharmacological activities of mango (Mangifera indica): A review. J Pharmacogn Phytochem 2016;5:1.

6. El-Hawary SS, Rabeh MA. Mangifera indica peels: A common waste product with impressive immunostimulant, anticancer and antimicrobial potency. J Nat Sci Res 2014;4:102-115.

7. Masibo M, He Q. Major mango polyphenols and their potential significance to human health comprehensive reviews. Food Sci Food Saf 2008;7:309-19.

8. Parmar NS, Parmar S. Anti-ulcer potential of flavonoids. Indian J Physiol Pharmacol 1998;42:343-51.

9. Verma VK, Singh N, Saxena P, Singh R. Anti-ulcer and antioxidant activity of Moringa oleifera (Lam) leaves against aspirin and ethanol induced gastric ulcer in rats. Int Res J Pharm 2012;2:46-57.

10. Alfky NA, Mustafa RA, Header EA, El Sawy NA, Al-Kushi AG. Antiulcer activities of Commiphora molmol (Myrrh) extract in male rats. Open J Gastroenterol 2016;6:300

11. Adinortey MB, Ansah C, Galyuon I, Nyarko A. In vivo models used for evaluation of potential antigastroduodenal ulcer agents. Ulcers 2013;2013:1-12.

12. Severi JA, Lima ZP, Kushima $H$, Brito AR, Santos LC, Vilegas $W$, et al. Polyphenols with antiulcerogenic action from aqueous decoction of mango leaves (Mangifera indica L.). Molecules 2009;14:1098-110.

13. Lima ZP, Severi JA, Pellizzon CH, Brito AR, Solis PN, Cáceres A, et al. Can the aqueous decoction of mango flowers be used as an antiulcer agent? J Ethnopharmacol 2006;106:29-37.
14. Kagbo HD, Aduku O. Evaluation of anti-ulcer effects of the methanol extract of Mangifera indica L Stem bark. Eur J Med Plants 2015;7:1.

15. Chroboková E, Raddová J, Vachůn M, Krška B, Pidra M. An analysis of apricot cultivars by random amplified polymorphic DNA and microsatellite primers. Hort Sci(Prague) 2011;38:125-33.

16. Caballero B, Trugo LC, Finglas PM. Encyclopedia of Food Sciences and Nutrition: Academic. Netherlands: Elsevier Science B.V.; 2003.

17. Del Sal G, Manfioletti G, Schneider C. The CTAB-DNA precipitation method: A common mini-scale preparation of template DNA from phagemids, phages or plasmids suitable for sequencing. Biotechniques 1989;7:514-20.

18. Levin RE, Ekezie FG, Sun DW. DNA-based technique: Polymerase chain reaction (PCR). In: Modern Techniques for Food Authentication. Academic Press: Elsevier; 2018. p. 527-616.

19. Singleton VL, Orthofer R, Lamuela-Raventós RM.Analysis of total phenols and other oxidation substrates and antioxidants by means of folin-ciocalteu reagent. Methods Enzymol 1999;299:152-78.

20. Geissman T, Waiss AC Jr. The total synthesis of (+)-retronecine. J Org Chem 1962;27:139-42.

21. Mattila P, Astola J, Kumpulainen J. Determination of flavonoids in plant material by HPLC with diode-array and electro-array detections. J Agric Food Chem 2000;48:5834-41.

22. Goupy $P$, Hugues M, Boivin P, Amiot MJ. Antioxidant composition and activity of barley (Hordeum vulgare) and malt extracts and of isolated phenolic compounds. J Sci Food Agric 1999;79:1625-34.

23. Lorke D. A new approach to practical acute toxicity testing. Arch Toxicol 1983;54:275-87

24. Shay $\mathrm{H}$. A simple method for the uniform production of gastric ulceration in the rat. Gastroenterology 1945;5:43-61.

25. Corne SJ, Morrissey SM, Woods RJ. Proceedings: A method for the quantitative estimation of gastric barrier mucus. J Physiol 1974;242:116P-7P.

26. Winzler RJ. Determination of serum glycoproteins. Methods Biochem Anal 1955;2:279-311.

27. Ezzat SM, El Sayed AM, Salama MM. Use of random amplified polymorphic DNA (RAPD) technique to study the genetic diversity of eight aloe species. Planta Med 2016;82:1381-6.

28. Maldonado-Celis ME, Yahia EM, Bedoya R, Landázuri P, Loango N, Aguillón J, et al. Chemical composition of mango (Mangifera indica L.) fruit: Nutritional and phytochemical compounds. Front Plant Sci 2019;10:1073.

29. Husain FM, Ahmad I, Al-Thubiani AS, Abulreesh HH, AlHazza IM, Aqil F. Leaf extracts of Mangifera indica L. inhibit quorum sensing - Regulated production of virulence factors and biofilm in test bacteria. Front Microbiol 2017;8:727.

30. Gouvea DR, Gobbo-Neto L, Sakamoto HT, Lopes NP, Lopes JL, Meloni F, et al. Seasonal variation of the major secondary metabolites present in the extract of Eremanthus mattogrossensis Less (Asteraceae: Vernonieae) leaves. Química Nova 2012;35:2139-45.

31. Carvalho AC, Guedes MM, de Souza AL, Trevisan MT, Lima AF, Santos FA, et al. Gastroprotective effect of mangiferin, a xanthonoid from Mangifera indica, against gastric injury induced by ethanol and indomethacin in rodents. Planta Med 2007;73:1372-6.

32. de Lira Mota KS, Dias GE, Pinto ME, Luiz-Ferreira Â, Monteiro Souza-Brito AR, Hiruma-Lima CA, et al. Flavonoids with gastroprotective activity. Molecules 2009;14:979-1012 